\title{
Pengendalian Kebisingan Dari Aktivitas Penerbangan di Lingkungan Sekitar Bandara Sultan Thaha Jambi dengan Pemanfaatan Ruang Terbuka Hijau
}

\author{
Nur Sodiq ${ }^{1}$, G. M. Saragih ${ }^{2}$, dan Peppy Herawati ${ }^{3 *}$ \\ Program Studi Teknik Lingkungan, Fakultas Teknik, Universitas Batanghari \\ Jalan Slamet Riyadi, Broni, Kota Jambi, 36122 \\ *e-mail : peppy.herawati@gmail.com
}

\begin{abstract}
Noise is a sound pollution and its existence is undesirable in a certain level and time, which has the potential to cause human health problems and environmental comfort. One of the causes of noise levels is due to airport operational activities, from landing to take off. For this reason, it is necessary to control the noise around the Sultan Thaha Jambi airport area, by utilizing green open space as a barrier that can reduce noise levels. This study aims to determine the level of airport noise in certain zones and evaluate the existence of green open space (RTH) whether it is appropriate to become a natural barrier as a barrier to reduce noise caused by flight activities from Sultan Thaha Jambi airport. The results showed the noise level $d B(A)$ from flight activities in each zone, namely the lowest in zones 1 and 3, amounting to $52.08 d B(A)$, and the highest in zone 5 at $87.93 \mathrm{~dB}(\mathrm{~A})$., while the existence of Green Open Space (RTH) is only in zone 1, and 3 are forest park areas, and fields around the Sultan Thaha Jambi airport area, so the existence of this Green Open Space (RTH) is able to reduce noise levels by $2.11 \mathrm{~dB}(\mathrm{~A})$ based on KEP48 / MNLH / 11/1996 the quality standard of the allowable noise level is $50 \mathrm{~dB}(\mathrm{~A})$. While zone 5 is a residential area, the noise level figure is quite high, namely $87.93 \mathrm{~dB}(A)$, due to the densely populated area, lack of green open space (RTH), and proximity to motorized vehicle transportation activities, and adjacent to the runway. runway airport. However, not all activities are carried out continuously. So that the residential area is still feasible if exposed to noise exposure either from airport activities or other activities.
\end{abstract}

Keywords: Airport; Green Open Space; Noise Level

\section{Pendahuluan}

Pengaruh kebisingan yang terus-menerus dari aktivitas operasional bandara, sangat memberikan efek negatif seperti, efek fisiologi dan efek psikologis terhadap manusia dan makhluk hidup disekitarnya. Kebisingan akan berpotensi menganggu kesehatan masyarakat disekitar bandara apabila masyarakat terpapar suara/bunyi kebisingan dalam periode yang lama dan terus menerus. Salah satunya yang berpotensi terjadi di Bandara Sultan Thaha yang ada di Kota Jambi. Bandara ini beroperasi dengan jadwal penerbangan perharinya sebanyak 23 kali penerbangan dari jenis pesawat yang berbeda, dan aktivitas penerbangan dibandara ini setiap harinya beroperasi dari mulai pukul 07.00 wib hingga jam 19.30 wib. Pengendalian kebisingan sangat diperlukan agar subjek yang terkena dampak kebisingan tidak terpapar terusmenerus. Pengendalian terhadap kebisingan dapat dilakukan dengan tiga metode yaitu pengendalian terhadap sumber kebisingan, pengendalian pada medium, dan pengendalian pada penerima.

Oleh sebab itu penelitian ini bertujuan untuk mengupayakan identifikasi sumber kebisingan dari aktifitas pesawat dari mulai landing hingga take off dan evaluasi pengendalian kebisingan di lingkungan bandara yang mencakup pengendalian kebisingan terhadap permukiman dan juga untuk lingkungan sekitar bandara. Upaya ini dilakukan untuk megendalikan kebisingan di lingkungan Bandara agar, maka dari itu perlu dilakukan identifikasi masalah kebisingan di Bandara, dan menentukan tingkat kebisingan yang diterima oleh permukiman sekitar Bandara.

\section{Metode Penelitian}

Dalam penelitian ini, penulis menggunakan penelitian kuantitatif. Setiap variabel yang ditentukan dan diukur dengan memberikan simbol-simbol dan angka yang berbeda-beda sesuai dengan kategori pada informasi yang berkaitan dengan variabel tersebut. Dengan menggunakan simbol-simbol atau angka tersebut, teknik perhitungan secara kuantitatif matematik bisa di lakukan sehingga bisa menghasilkan suatu kesimpulan yang belaku umum di dalam suatu parameter.

\section{Pengambilan Sampel}

Pengambilan Sampel dilakukan dengan cara sederhana menggunakan sebuah integrating sound level meter yang mempunyai fasilitas pengukuran Ltm5, yaitu Leq dengan waktu ukur setiap 5 detik, dilakukan pengukuran selama 10 (sepuluh) menit. Dengan fasilitas ini LAeq,T sudah didapat dibaca langsung pada sound level meter. Lokasi pengambilan sample dilakukan pada titik-titik zona, yang kemudian dipetakan luas sebaran kebisingan yang memperngaruhi kawasan bandara dan permukiman.

Untuk setiap pengukuran pada tiap sample harus dapat mewakili selang waktu tertentu dengan menetapkan paling sedikit 4 waktu pengukuran pada siang hari dan pada malam hari paling sedikit 3 waktu pengukuran, kemudian dilanjutkan dengan menghitung tingkat kebisingan pada siang hari (LS) selama 16 jam, dan tingkat kebisingan pada malam hari (LM) selama 8 jam, setelah data tingkat kebisingan pada siang hari dan malam hari didapat, kemudian dilanjutkan dengan menghitung rata-rata tingkat kebisingan dalam satu hari atau (LSM). Titik lokasi pengukuran terdiri dari 5 Zona yaitu :

1. Zona 1 diarea lapangan Sultan Thaha, Kota Jambi, dengan jarak titik pengukuran pada saat pesawat landing sejauh $600 \mathrm{~m}$, dan pada saat pesawat take-off sejauh $970 \mathrm{~m}$; 
2. Zona 2 diarea Parking Areal Mobil, dengan jarak titik pengukuran pada saat pesawat landing sejauh $200 \mathrm{~m}$, dan saat pesawat take-off sejauh $550 \mathrm{~m}$;

3. Zona 3 diarea taman hutan, dengan jarak titik pengukuran pada saat pesawat landing sejauh $400 \mathrm{~m}$, dan saat pesawat take-off sejauh $670 \mathrm{~m}$;

4. Zona 4 diarea Apron parkiran pesawat, dengan jarak titik pengukuran pada saat pesawat landing sejauh $50 \mathrm{~m}$, dan saat pesawat take-off sejauh $360 \mathrm{~m}$;

5. Zona 5 diarea permukiman penduduk dengan jarak titik pengukuran pada saat pesawat landing sejauh $700 \mathrm{~m}$, dan saat pesawat take-off sejauh $400 \mathrm{~m}$;

\section{Analisis Dan Pembahasan Data Tingkat Kebisingan (Leq)}

Pengambilan data pengukuran nilai kebisingan dilakukan di beberapa titik yang sebelumnya telah ditentukan pada kawasan Bandara Sultan Thaha dan areal permukiman penduduk sekitar kawasan Bandara,Kota Jambi, berdasarkan KEPMENLH No.48/MenLH/11/1996, setiap pengukuran pada sample harus dapat mewakili selang waktu tertentu dengan menetapkan paling sedikit 4 waktu pengukuran pada siang hari dan malam hari paling sedikit 3 waktu pengukuran, dikarenakan operasional Bandara Sultan Thaha Jambi hanya selama 13 jam maka kriteria pengukuran dalam penelitian ini sebagai berikut :

1. L1 diambil pada jam 08.00 mewakili Jam 06.00 - 09.00;

2. L2 diambil pada jam 10.00 mewakili Jam 09.00 - 11.00;

3. L3 diambil pada jam 12.00 mewakili jam $14.00-17.00$;

4. L4 diambil pada jam 14.00 mewakili jam $17.00-22.00$;

5. L5 diambil pada jam 15.00 mewakili jam $22.00-24.00$;

6. L6 diambil pada jam 16.00 mewakili jam 24.00 - 03.00;

7. L7 diambil pada jam 18.00 mewakili jam $03.00-06.00$.

Waktu dalam pengukuran dilakukan selama 10 menit tiap jam sampling. Pengambilan atau pencatatan data dilakukan setiap 5 detik dalam kurun waktu selama 10 menit, sehingga rata-rata data yang didapat sebanyak 120 data yang selanjutnya dilakukan perhitungan data, untuk mengetahui nilai kebisingan hasil pengukuran. Perhitungan data $\mathrm{L}_{\mathrm{eq}}$ per-1 menit dengan persamaan :

$L_{\text {eq }}(1$ menit $)=10 \log \frac{1}{60}\left[\left(10^{0,1 L_{1}}+10^{0,1 L_{2}}+\cdots+10^{0,1 L_{12}}\right) 5\right] d B(A)$

Persamaan diatas digunakan pada setiap menit hingga diperoleh data $\mathrm{L}_{\mathrm{eq}} 1$ menit sampai 10 menit. Setelah masingmasing nilai Leq 1 menit diperoleh, maka dilanjutkan dengan perhitungan Leq 10 menit dengan persamaan berikut :

$L_{\text {eq }}(10$ menit $)=10 \log \frac{1}{60}\left[\left(10^{0,1 L_{I}}+10^{0,1 L_{I I}}+\cdots+10^{0,1 L_{X}}\right) 1\right] d B(A)$

Setelah di hitung dengan persamaan diatas maka dilanjutkan dengan memperoleh nilai rata-rata dari hasil pengukuran Leq selama 24 jam. Hasil kemudian dihitung untuk Leq siang hari (LS), pengukuran dilakukan dari perwakilan jam 06.00 - 22.00, sedangkan pengukuran Leq malam hari (LM) dilakukan dari jam 22.00 - 06.00, Persamaannya adalah sebagai berikut :
$L_{\S}=10 \log \frac{1}{16}\left[\left(T_{L} 10^{0,1 \cdot L_{m}}+T_{d} 10^{0,1 L_{u}}\right] d B(A)\right.$
$L_{M}=10 \log \frac{1}{g}\left[\left(T_{e} 10^{0,1 L_{w}}+T_{f} 10^{0,1 L_{f}}+T_{g} 10^{0,1 L_{g}}\right] d B(A)\right.$

Untuk mendapatkan data rata-rata dalam 1 hari dihitung dari hasil pengukuran siang dan malam hari yang digabungkan untuk mendapatkan tingkat kebisisngan ditambah dengan faktor pembobotan menurut konsep ISO 9001, yaitu $5 \mathrm{Db}(\mathrm{A})$, dalam persamaannya adalah sebagai berikut :

$$
L_{S M}=10 \log \frac{1}{24}\left(16 \times 10^{0,1 L_{m}}+8 \times 10^{0, L}\left[L_{M}+5\right)\right) d B(A)
$$

keterangan :

1. $\mathrm{L}_{\text {eq }}$ : kebisingan ekivalen $\mathrm{dB}(\mathrm{A})$;

2. $\mathrm{L}_{1}, \ldots, \mathrm{L}_{12}=$ kebisingan setiap 5 detik selama 60 detik $\mathrm{dB}$ (A);

3. $\mathrm{L}_{\mathrm{I}}, \ldots ., \mathrm{L}_{\mathrm{X}}=$ kebisingan setiap 1 menit selama 10 menit $\mathrm{dB}$ (A);

4. $\mathrm{La}, \ldots . . ., \mathrm{Ld}=\mathrm{Leq}(10$ menit $)$ setiap selang waktu di pagi hari $\mathrm{dB}(\mathrm{A})$;

5. $\mathrm{L}_{\mathrm{S}}=\mathrm{L}_{\mathrm{eq}}$ disiang hari $\mathrm{dB}(\mathrm{A})$;

6. $\mathrm{Ta}, \ldots . ., \mathrm{Td}=$ rentang waktu pengukuran disiang hari $(\mathrm{jam})$;

7. $\mathrm{L}_{\mathrm{M}}=\mathrm{L}_{\mathrm{eq}}$ di malam hari $\mathrm{dB}(\mathrm{A})$;

8. $\mathrm{Te}, \ldots . ., \mathrm{Tg}=$ rentang waktu pengukuran dimalam hari (jam);

9. $\mathrm{Le}, \ldots . ., \mathrm{Lg}=\mathrm{L}_{\mathrm{eq}}(10$ menit $)$ setiap selang waktu dimalam hari $\mathrm{dB}(\mathrm{A})$;

10. $\mathrm{Lsm}=$ Leq pada pengukuran $24 \mathrm{jam} \mathrm{dB}(\mathrm{A})$.

\section{Hasil Dan Pembahasan}

\section{Perhitungan Tingkat Kebisingan (Leq ), Selama 1 Menit dan 10 Menit}

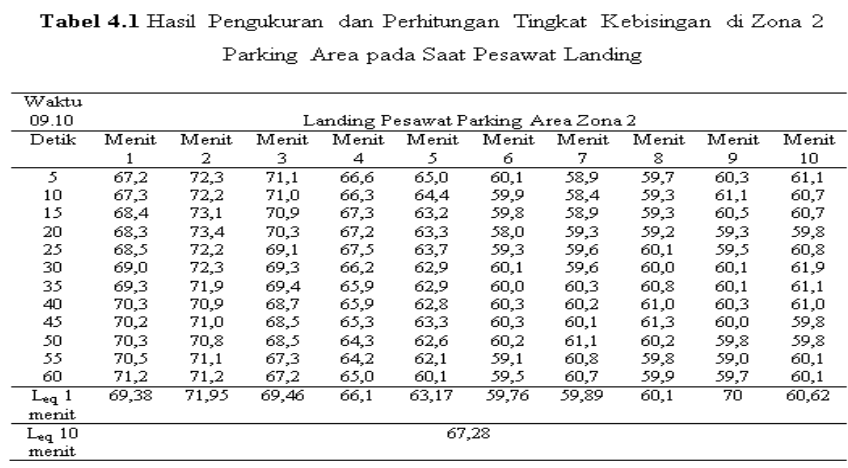

Tabel 4.1 diatas adalah hasil dari pengukuran kebisingan dilokasi parking area titik pengukuran zona 2, yang diambil pada saat pesawat landing hasil pengukuran yang berfluktasi setiap 5 detik diambil selama sepuluh menit dengan ketentuan dalam 1 menit menurut perhitungan sebagai berikut : 


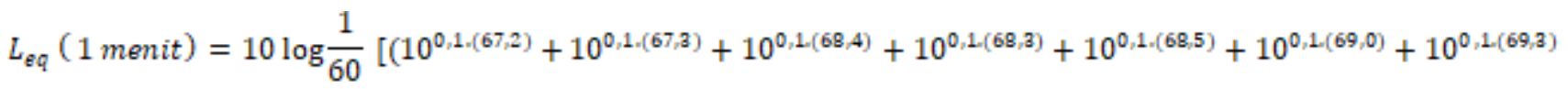

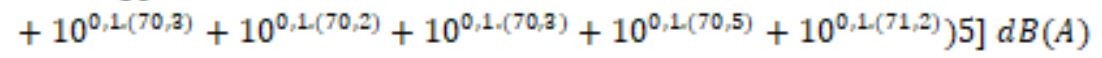

$$
\begin{aligned}
& =69,38 \mathrm{~dB}(\mathrm{~A})
\end{aligned}
$$

Perhitungan diatas untuk rata-rata data yang dihitung selama satu menit didapat pada menit pertama sebesar 69,38 $\mathrm{dB}(\mathrm{A})$, seterusnya dapat dilihat pada tabel 4.1, untuk perhitungan selama 10 menit maka menggunakan persamaan sebagai berikut :

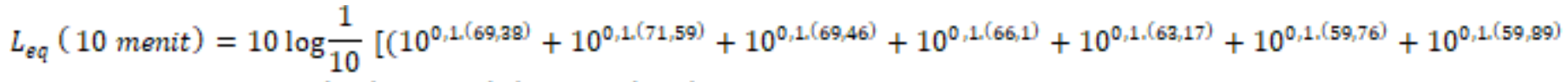

$$
\begin{aligned}
& \left.\left.+10^{0,1 / 60,1)}+10^{0,1(70)}+10^{0,1[60,62)}\right) 1\right] d B(A)=67,28 d B(A)
\end{aligned}
$$

Hasil diatas merupakan perhitungan selama sepuluh menit dimana pada saat pesawat melakukan landing didapat angka tingkat kebisingan sebesar 67,28 dB(A),

\section{Perhitungan Tingkat Kebisingan Pada Siang dan Malam Hari (LSM ), Selama 24 Jam}

Perhitungan data LSM atau tingkat kebisingan yang didapat dalam satu hari, dimana data tingkat kebisingan pada siang hari, digabungkan dengan tingkat kebisingan pada malam hari, ditambah dengan faktor pembobotan, yaitu 5 $\mathrm{dB}(\mathrm{A})$ adalah sebagai berikut :

$$
\begin{aligned}
L_{S M} & =10 \log \frac{1}{24}\left[\left(16 \times 10^{0,11\left(L_{S}\right)}+8 \times 10^{0,1 .\left(L_{M}+5\right)}\right)\right] d B(A) \\
L_{S M} & =10 \log \frac{1}{24}\left[\left(16 \times 10^{0,11(56,32)}+8 \times 10^{0,1 /\left(57_{2}, 05+5\right)}\right)\right] d B(A) \\
& =59,14 \mathrm{~dB}(\mathrm{~A})
\end{aligned}
$$

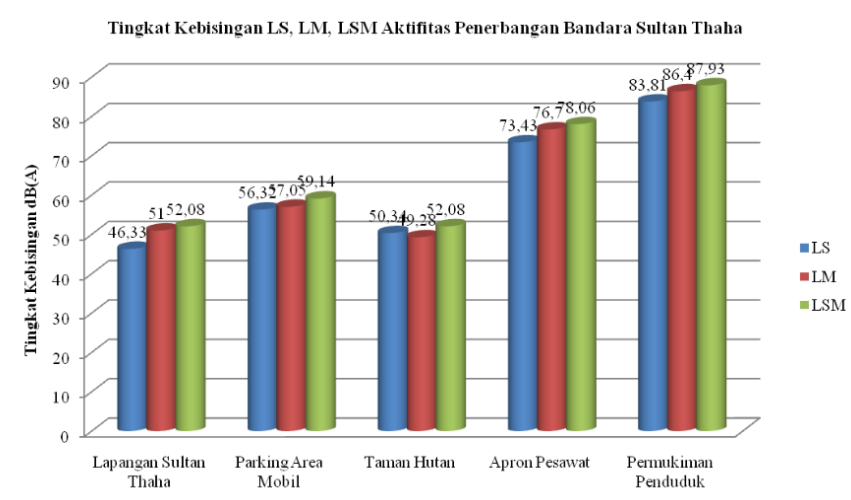

Gambar 4.2 Data Tingkat Kebisingan Aktifitas Penerbangan di 5 Zona Titik Lokasi Pengukuran untuk Waktu Perhitungan LS, LM, dan LSM

Tabel 4.2 Rekapitulasi Perhitungan Tingkat Kebisingan Bandara untuk Waktu LS, LM, dan LSM

\begin{tabular}{llcccc}
\hline \multicolumn{1}{c}{ Zona } & LS & LM & LSM & $\begin{array}{c}\text { Baku } \\
\text { Mutu }\end{array}$ \\
\hline 1 & Lapangan Sultan Thaha & 46,33 & 51 & 52,08 & 50 \\
2 & Parking Area Mobil & 56,32 & 57,05 & 59,14 & 80 \\
3 & Taman Hutan & 50,34 & 49,28 & 52,08 & 50 \\
4 & Apron Pesawat & 73,43 & 76,7 & 78,06 & 80 \\
5 & Permukiman Penduduk & 83,81 & 86,4 & 87,93 & 55 \\
\hline
\end{tabular}

\section{Evaluasi Kebutuhan Ruang Terbuka Hijau Sebagai Barrier Alami}

Barrier alami adalah jenis penghalang kebisingan yang terdiri dari tanaman yang tumbuh dari atas pucuk sampai bawah. Barrier dapat terbuat dari tanaman semak, perdu, atau pun pohon, tingkat reduksi kebisingan dapat digunakan persamaan (beranek,1971)

Dimana :

Atenusiasi $=(0,8 \log \mathrm{f}-0,31) \mathrm{r}$

$\mathrm{f}=$ frekuensi $(\mathrm{Hz})$

$\mathrm{r}=$ jarak antara sumber kebisingan dengan barrier

Barier alami ini terletak di zona 1 area lapangan Sultan Thaha dan zona 3 di taman hutan kawasan area bandara sultan thaha, dimana terdapat tumbuhan berupa tanaman hias dan pohon, menurut Thajono.N dan Nugroho.I (2018), tanaman hias dapat digunakan sebagai alternatif barrier atau penghalang dalam mereduksi tingkat kebisingan, dimana penurunan atau reduksi dari tanaman hias adalah sebagai berikut :

Tabel 4.4 RTH sebagai Barrier Alami Zona 1-3 pesawat landing dan take off

\begin{tabular}{ccccc}
\hline $\begin{array}{c}\text { Zona Rata-rata } \\
1-3 \mathrm{~d}(\mathrm{~A})\end{array}$ & Barrier alami & Tingkat Reduksi & $\begin{array}{c}\text { Rata-Rata } \\
\text { Reduksi dB(A) }\end{array}$ & Baku Mutu \\
\hline \multirow{3}{*}{52,08} & Pucuk Merah & $12 \%$ & 50,7 & \\
& Wali Songo & $12 \%$ & 50,7 & 50 \\
& Soka & $13 \%$ & 50,1 & \\
& Imodia & $16 \%$ & 48,38 & \\
\hline TOT $\mathrm{AL}$ & & & 49,97 & \\
\hline
\end{tabular}

\section{Kesimpulan}

1. Tingkat kebisingan yang terjadi di Bandara Sultan Thaha Kota Jambi, terdiri dari 5 Zona pengukuran yaitu; Zona 1 sebesar 52,08 $\mathrm{dB}(\mathrm{A})$, baku mutu yang diperbolehkan sebesar $50 \mathrm{~dB}(\mathrm{~A})$; Zona 2 sebesar 59,14 dB(A), baku mutu yang diperbolehkan $80 \mathrm{~dB}(\mathrm{~A})$; Zona 3 sebesar 52,08 dB(A) baku mutu yang diperbolehkan $50 \mathrm{~dB}(\mathrm{~A})$; Zona 4 sebasar 78,06 $\mathrm{dB}(\mathrm{A})$, baku mutu yang diperbolehkan $80 \mathrm{~dB}(\mathrm{~A})$; Zona 5 sebesar 87,93 $\mathrm{dB}(\mathrm{A})$, baku mutu yang diperbolehkan $55 \mathrm{~dB}(\mathrm{~A})$;

2. Evaluasi terhadap kebutuhan Ruang Terbuka Hijau seluas 2,3 Ha, dimana peruntukannya sebagai Barrier alami yaitu, penghalang atau dapat mereduksi tingkat kebisingan dibandara Sultan, dengan nilai rata-rata $\mathrm{dB}(\mathrm{A})$ dalam satu hari (LSM), sebesar 52,08 $\mathrm{dB}(\mathrm{A})$, setelah tereduksi menurun menjadi 49,97 dB(A). dengan standar baku mutu 
Nur Sodiq, G. M. Saragih dan Peppy Herawati, Pengendalian Kebisingan Dari Aktivitas Penerbangan di Lingkungan Sekitar Bandara Sultan Thaha Jambi dengan Pemanfaatan Ruang Terbuka Hijau

untuk kawasan RTH sebesar 50 dB(A). Pada zona 2,4,dan 5 sebaiknya diberikan barrier alami berupa semak/perdu seperti pucuk merah dan lain-lain, karena tanaman ini mampu mereduksi kebisingan sebesar $12 \%$, yang sebaiknya ditanam di pekarangan rumah.

\section{Ucapan Terima Kasih}

Penulis mengucapkan terimakasih atas terlaksananya penelitian ini dimana selama proses penyelesaian jurnal ini penulis memperoleh bantuan, bimbingan, pengarahan, dan support dari berbagai pihak terutama Pembimbing Tugas Akhir Bapak Drs.G.M.Saragih, M.Si selaku Dosen Pembimbing I dan Ibu Peppy Herawati, ST, MT selaku Dosen Pembimbing II yang telah memberikan pengarahan, bimbingan, dan masukan dalam jurnal ini.

\section{Daftar Pustaka}

Harrington, \& Gill, 2005. Buku Saku Kesehatan Kerja. Jakarta : EGC

Thajono.N dan Nugroho.I (2018), Jurnal Penelitian Seminar Nasional “ Tanaman Hias Sebagai Peredam Kebisingan”, Universitas Widiyagama Malang.

Kementerian Lingkungan Hidup RI. 1996. Keputusan Menteri Negara Lingkungan Hidup Nomor KEP48/MENLH/11/1996 tentang Baku Tingkat Kebisingan. Jakarta.

Sasongko, D., dkk. 2000. Kebisingan Lingkungan. Semarang: Badan Penerbit Universitas Diponegoro. 